\title{
Research on the Artistic Feature Trend of Fashion Photography under the Influence of Conceptual Art
}

\author{
Qiming Wang \\ School of Fine Arts \\ Anshan Normal University \\ Anshan, China
}

\begin{abstract}
It must be inevitable for conceptual art to prosperously develop in the period of postmodernist culture, which is the side reflection of the cultural and social public concern in this period, so the idea essence of the conceptual art and its way of expression have a profound impact and mutual integration and reflection on both people's daily life and other art categories. At the same time, in this period, under the influence of post-modern culture, the art of fashion photography also begins to take off the simple form of beautiful appearance and pays attention to the expression of concept, based on which fashion photography art continuously expands its influence, not limited to the promotion of fashion products and the spread of fashion concept. Like the conceptual art, it begins to focus on politics, environmental protection, cultural conflict, human survival and many other issues, reflecting the more sociological and cultural significance. Base on this, the topic further discusses and studies the expressional features of fashion photography art with conceptual performance.
\end{abstract}

Keywords-conceptual art; fashion photography; postmodernism

\section{INTRODUCTION}

Fashion photography art is an industry of constant innovation, with its eternal goal of breaking the routine visual expression form, promote by the majority of the audience. In the major context of postmodern culture and art, the fashion photography hardly influences people's visual nerve only by the past way of expressing beautiful figure in magnificent lighting and gorgeous color. It is difficult to have new ideas only form the Simple form, but the conceptual performance focuses on people's mind feeling and just can break the barrier for expression of fashion photography art. While fashion photography art, after all, has its own visual expression language, the conceptual expression is not equivalent to the art of concept, so we have to discuss the feature trend of fashion photography art under the influence of conceptual art as the following.

\section{HUMANISM}

Like most of the postmodernist arts, Fashion photography began to pay attention to politics, environmental protection, anti-war, gender, race, cultural differences and many other social issues. In its conceptual performance, fashion photography changed the past simple commercial propaganda and began to pay more attention to people, and from the humanism, it used its special charm of video vision to show the humanistic care and reflect the characteristics of the times. That is to say, good fashion photography must touch the viewer's heart in a way, at least something he can not do, a view he never seen or an emotion he has not concerned about. Roland Bart has said a word in his analysis of wonderful photos, "it hits me somewhere, stinging me." [1] The "hit" and "sting" means the internal concept the work and the author's humanistic standpoint. Of course, on the other hand it is involved that the fashion brand would promote the brand culture and set up special social image for brand through the humanitarian culture.

In this regard, the most prominent that we have to mention is the Italian fashion brand Benetton (BENETTON), which has had a huge shock and appeal in the media and society through many years' fashion photography advertising of conceptual performance. These works pay attention to the contradictions and reality of race and social harmony, war, AIDS and environment and others. These works use models in different national background and face the audience in the most direct and primitive way. For them, there is controversy in different countries, but they also attract a wide attention and are recognized in different countries to make Benetton become one of the fastest growing companies in the world. Benetton's fashion photography advertising has long been beyond the scope of business and become a conceptual art of fashion photography. These pictures have a deep cultura connotation, embody the humanistic care, and break away from overelaborate embellishment and affected pose of the past fashion brand clothing model. [2]

The simple business advocacy, the social issues exploration in different social strata and even the bold application of conceptual content are omnipresent in Benetton's fashion photography works. the baby with umbilical cord uncut, the juxtaposition of hearts of threecolor race, kiss between nun and priest, the prisoner facing the death, the final farewell of dying AIDS patient and his loved ones, the bloody trousers and T shirt of the soldiers fell in battle, the seabirds stained with oil contamination that can not fly ... these images are innovative so that they may be not caught up even by some avant-garde conceptual art "Fig. 1". 

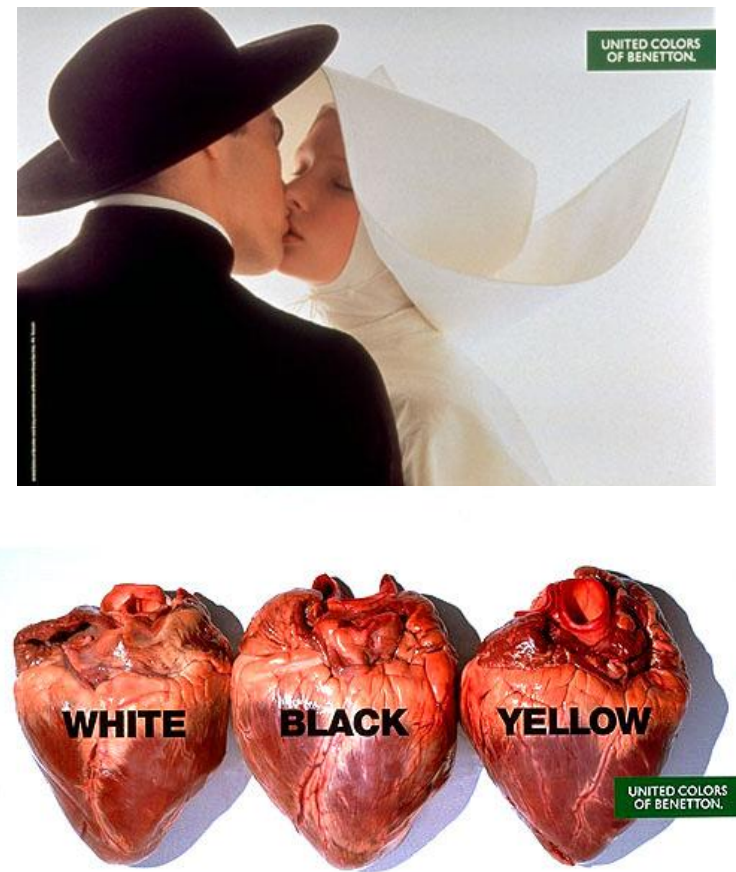

Fig. 1. Benetton advertising.

Affected by it, the domestic fashion photographer also began to pay attention to this. For a fashion blockbuster, ELLE invited famous movie star $\mathrm{Yu}$ Nan and 12 supermodels to appear in nude, shot by the famous fashion photographer Chen Man. The theme of this work is to advocate environmental protection by dint of the power of purity, embracing the mother earth. We all know the earth had been as pure as a baby is just born when it was not contaminated, where is covered with green forests and inlaid with quiet springs. Today, as children of the earth, people have asked too much for the mother earth, and now we should trace to its source and let it go back to its original. We have to abandon all bright and gorgeous costumes as well as various accessories, appearing in a natural posture just as we are born; in this way, will we call back people's love and maintenance for the earth? "Fig. 2"
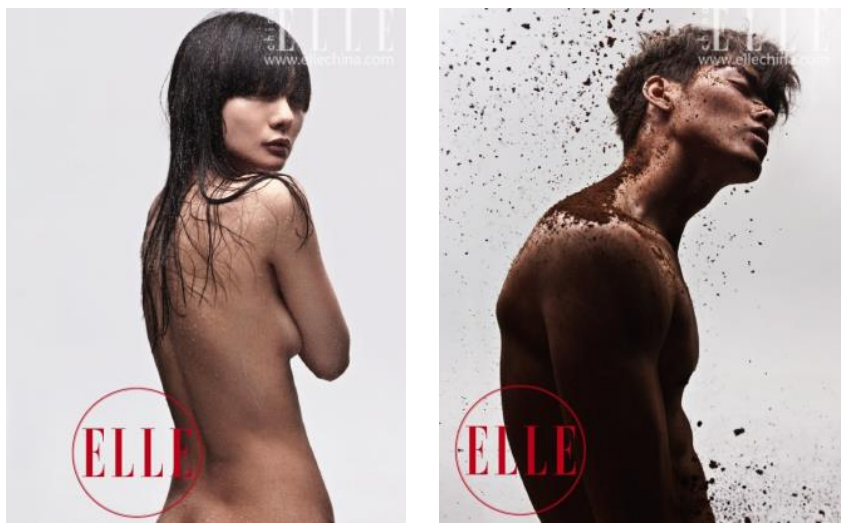

Fig. 2. The works of Chen Man.
In addition, some works of fashion photography emphasize the concerns on disadvantaged groups. Japanese photographer Takamatsu Hideaki shot a group of fashion works that show the street tramps, in which the models all are real tramps, wearing their usual clothes, without dress-up or decoration. The author also carefully taught the tramps to make a variety of fashion pose, changing the sloppy and gloomy image of tramp into a fresh and stylish trendsetter. It reflects that the author desires to draw the attention of the community to the disadvantaged groups and treat them equally, as shown in "Fig. 3". Takamatsu says that he wants to shoot the most natural and true side of the street sleepers, attracting young women in Japan, letting them understand the cute side of these street sleepers, and putting aside the prejudice.
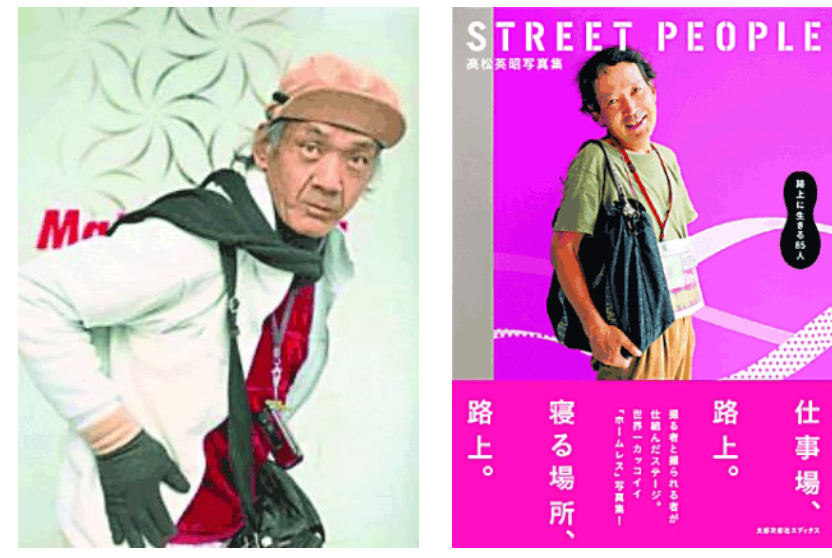

Fig. 3. Takamatsu Hideaki's works.

This chapter mainly analyzes the "humanistic" performance feature of fashion photography art under the influence of conceptual art, which has changed the single commercial propaganda and begun to pay more attention to people, and starting from the humanism, used special charm of video vision to show humanistic care, reflect the characteristics of the times, but reduce the direct publicity of products.

\section{SEXUAL AND EROTIC PERFORMANCE}

"Sex" is always an artistic content that is constantly focused by each category of art, so does it in conceptual art, and the fashion photography art is no exception as it emphasizes on the conceptual performance. For its psychological source, according to Freud's theory of psychology, sexual instinct is a basic motivation for artistic creation. Under the major background of the society, the fashion photography began to show sexual and erotic expression in its conceptual performance. In the 1960s, the rebellion of Western youth and the rise of the sexual liberation movement made people not guard the traditional ideas and not oppress the true feelings of sexual passion. Of course, this is also related to the traditional culture of the West and to the more tolerant ideological and cultural attitude of people with the economic development. As the leader of the social trend, fashion naturally takes a step faster. At the same time, the major fashion brand also gets an 
insight into this real human desire, and begins to use erotic fashion photography ads to meet this appeal of the audience, so as to achieve the purpose of brand publicity. The wellknown advertising expert Wilson Brianki has pointed out: "If you want to lure consumers in the advertising, you must intentionally set a vague sexual message in the ad, and of course, this performance can not exceed the limit of people to accept it, that is the boundary of perception. [3] Of course the "sex" here is not confined to the traditional definition, here it is a relatively broad definition, such as post-feminism, new male view, contradictory view on homosexual, healthy sexual behavior and so on. [4]

The most important figure in the fashion show is the fashion photography master Helmut Newton, who leads to this reform of sexual concept in fashion photography. Newton's photos with sexual awareness "have more eternal quality than the single fashion shot, but difficult to be instantly interpreted."[5] As one of the most prestigious rebels in the fashion circle, he is constantly exploring in his life, and his weird thinking space becomes a model of later generations for emulation. [6] In Newton's works, women are mostly placed beyond the current or non-eternal position, declaring their existence without consideration of time and space, as shown in "Fig. 4".
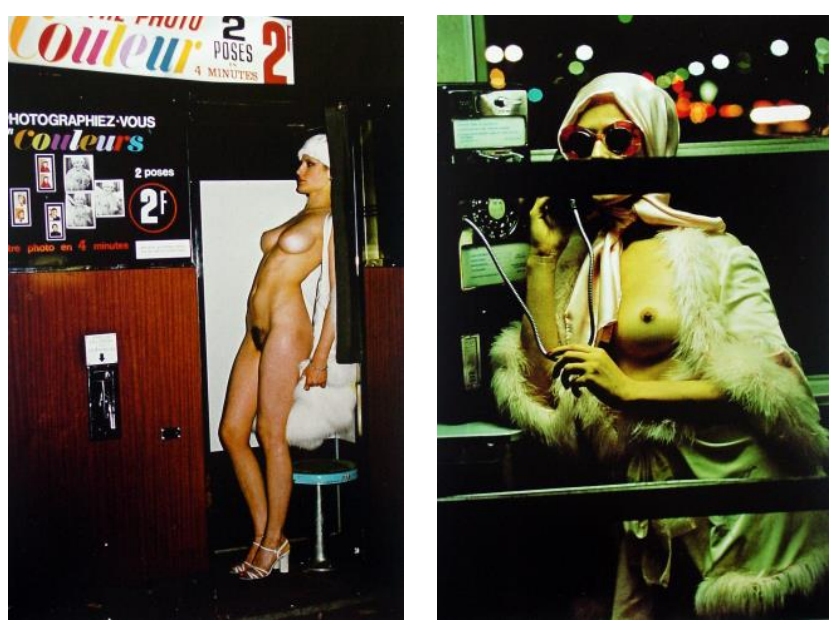

Fig. 4. Helmut Newton's works.

These bare female models show their seductive body, but full of inimitable self and self-confidence, from which we can not find any affected coquetry to attract the attention of men. They, in the bare body, look in the eyes of audience, with a sense of resistance, as if they compete to the maleoriented sexual concept. Newton's fashion photography of conceptual performance has such a disturbing provocation and fear effect, because a unusual, acute and even extreme conflict exist in the stalemate of these images.

In 2011, the Hollywood actress Megan Fox served a magazine for shooting a large vogue blockbuster, in which she appeared with red lips and flirted with the female puppet, as shown in "Fig. 5". In the pictures, Megan Fox stood together with a lifelike mannequin, and at first glance it is difficult to distinguish them. The elaborate model is so much like Megan Fox's true self-show after taking off disguise.
The pictures implied the discussion on "sexual desire" repressed in the mind. In the pictures, the doll is used to increase the mystery of the theme and the tension of the picture through the contrast of reality and fantasy.
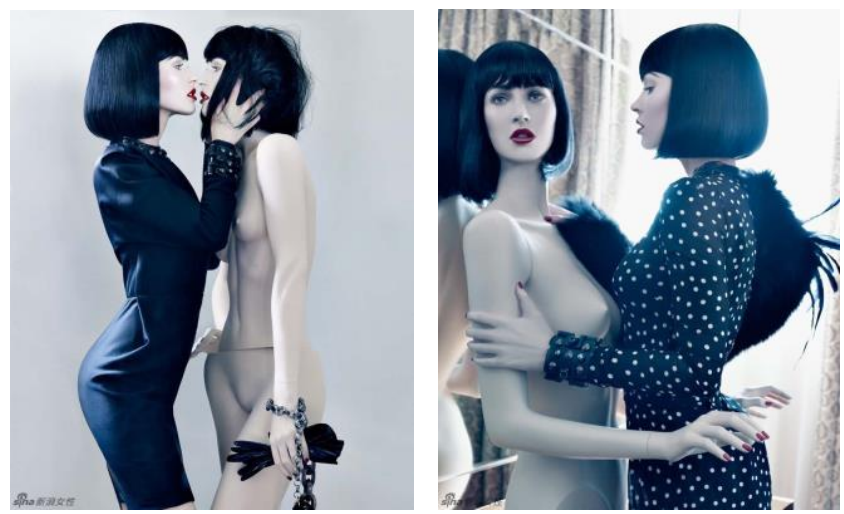

Fig. 5. Megan Fox.

Sexuality is one of the eternal themes of art expression, and this paper made a new interpretation of sexual concept through the fashion photography art in fashion photography works, breaking the superficial understanding and expression of sexuality, highlighting the respect for women and the thinking on the problem of sexual freedom, and enriching the performance of fashion photography and the further significance of works.

\section{THE CHARACTERISTICS OF FEMINISM}

Female is the object of fashion for its main performance, fashion and women female are inseparable. In a certain period of time, male leads the fashion photography, but these works are deeply marked with male view even if they are not of male supremacy. While the female photographer appeared and even developed into a certain number of groups, the fashion photography art began to be interpreted newly. These independent and confident individuals began to review the female's body and their inner interpretation. This confirms the early slogan of feminism that is "Our bodies belong to ourselves." At the same time, as the main consumers of fashion, the female's taste is naturally taken seriously. In order to cater to them, countless images of able women are created in fashion photography, who try to be preeminent, are independent and self-confident, all-round in work and family, have no tendency to rely on men. [7] Driven by the feminist concept, the fashion photography of conceptual performance uses the way of video to redefine the status, rights, identity ...of the female in the society. They are trying to change the status of the female in the past fashion photography works, in which the female was often treated in the viewpoint of male. In their works, no such element appears again to cater to the male's concept. At the same time, the works may deal with the social rights of male and female in the viewpoint of female, and even nurture male to explain their ideas. Here is a typical example, as shown in "Fig. 6". This series of works is shot by female photographer Harrette, whose works is created often in the view of gender to explore the relationship between gender and society. She 
is particularly good at shooting male body, and uses props to show the male body in vogue. In the female body photograph, there are a variety of beautiful scenes that male body is dressed up in different poses and with different expressions, to achieve the deep thinking on male body and social characteristics.

This chapter focuses on the increasing trend of female fashion photographers group. We find that under the influence of the conceptual arts, they begin to pay more attraction to the release of personality and the expression of individual ideas. Their works have a distinctive gender and personal interpretation, for example the different views of body and sex. At the same time, they also abandon the intended performance and the low-level stage of rebellion in the expression of a certain concept, and continuously deliver the creative expression of personal values.
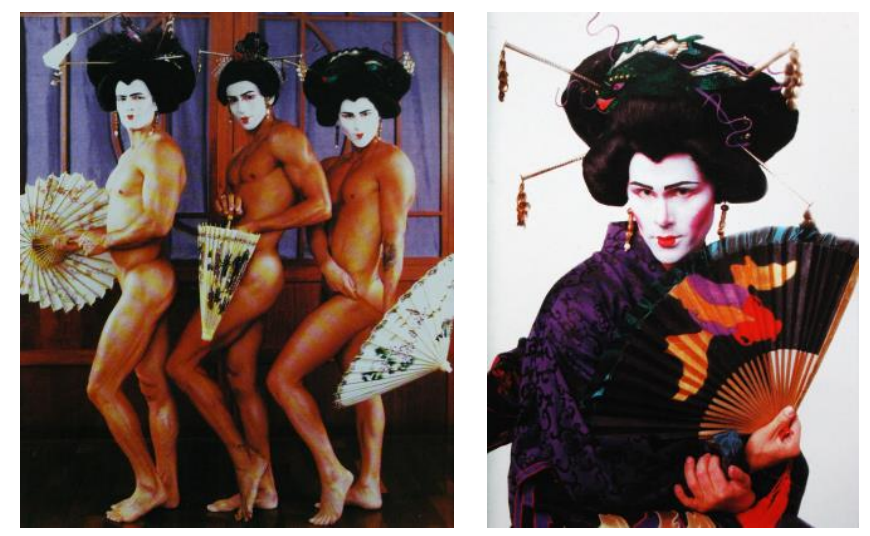

Fig. 6. "Geisha".

\section{CONCLUSION}

Under the influence of conceptual art, fashion photography art breaks the shackles of traditional aesthetic concepts and presents new performance characteristics. Its conceptual performance of fashion photography not only satisfies the demand of commercial propaganda, but also conveys the subjective thought of author, questioning and putting forward social issues such as human nature, morality, environmental protection, war, female and so on, as stated in the part of its characteristics of humanistic performance. This is consistent with the expression purpose of the conceptual art, not only enhancing their own ideological and artistic characteristics, but making it have the social responsibility and practical significance that the previous forms of fashion photography do not have.

\section{REFERENCES}

[1] Baokun. Watch and Watch [M]. Beijing: China Federation of Literary and Art Circles Press, 2009.299.

[2] Yang Lili. Study on Excellent Cases of Contemporary Fashion Advertising Photography Planning [J]. Art and Design .2008, (12): 139.

[3] Gulfport. Post-modernistic advertisement [J] .Advertising art.2011, (4): 19-23.
[4] Zhu Feihong. Study on the Expression of Conceptual Art in Contemporary Western Fashion Photography[D]. Zhejiang: Zhejiang University of Technology .2008.

[5] Anne Hollander. Woman in the mirror [M] .Munich: Schirmer Mosel, 2005.123.

[6] Lin Lu. Master's Fashion Photography [M]. Fuzhou: Fujian Science and Technology Press, 2010.10.

[7] Yang Lili. Aspects of Fashion, sex, gender and power in fashion images [J]. Oriental Art .2006, (2): 118.

[8] Dong Hua University (Natural Science), 2011.37(4):514-517. 